Open Access

\title{
Perinatal probiotic supplementation in the prevention of allergy related disease: 6 year follow up of a randomised controlled trial
}

\author{
Melanie Rae Simpson ${ }^{1 *}$, Christian Kvikne Dotterud ${ }^{1,2}$, Ola Storrø ${ }^{1}$, Roar Johnsen ${ }^{1}$ and Torbjørn Øien ${ }^{1}$
}

\begin{abstract}
Background: Perinatal probiotics supplementation has been shown to be effective in the primary prevention of atopic dermatitis (AD) in early childhood, although the long term effects of probiotics on AD and other allergic diseases is less certain. We have previously reported a significant reduction in the cumulative incidence of $A D$ at 2 years after maternal probiotic supplementation. In this study we present the effects of perinatal probiotics given to women from a general population on allergy related diseases in their offspring at 6 years.
\end{abstract}

Methods: Four hundred and fifteen pregnant women were randomised to receive probiotic or placebo milk in a double-blinded trial from 36 week gestation until 3 months postpartum. Probiotic milk contained Lactobacillus rhamnosos GG, L. acidophilus La-5 and Bifidobacterium animalis subsp. lactis Bb-12. At 6 years, children were re-assessed for $A D$, atopic sensitisation, asthma and allergic rhinoconjunctivitis (ARC).

Results: At 6 years, 81 and 82 children were assessed for AD in the probiotic and placebo groups, respectively. In a multiple imputation analysis, there was as trend towards a lower cumulative incidence of $A D$ in the probiotic group compared to the placebo group (OR 0.64, $95 \% \mathrm{Cl} 0.39-1.07, p=0.086 ; \mathrm{NNT}=10$ ). This finding was statistically significantly in the complete case analysis (OR $0.48,95 \% \mathrm{Cl} 0.25-0.92, p=0.027, \mathrm{NNT}=6)$. The prevalence of asthma and atopic sensitisation, and the cumulative incidence of ARC were not significantly affected by the probiotic regime at 6 years of age.

Conclusions: Maternal probiotic ingestion alone may be sufficient for long term reduction in the cumulative incidence of $A D$, but not other allergy related diseases.

Trial registration: ClinicalTrials.gov identifier: NCT00159523

Keywords: Allergy, Asthma, Atopic dermatitis, Paediatrics, Prevention, Probiotics, Rhinitis

\section{Background}

Atopic dermatitis (AD), asthma and allergic rhinoconjunctivitis (ARC) are a major cause of chronic disease in childhood. A revised version of the "hygiene hypothesis" suggests that the pattern of colonisation and the diversity of the intestinal microbiota may be an important factor in the increased prevalence of these diseases

\footnotetext{
* Correspondence: melanie.simpson@ntnu.no

'Department of Public Health and General Practice, Faculty of Medicine, Norwegian University of Science and Technology (NTNU), Postboks 8905, MTFS, 7491, Trondheim, Norway

Full list of author information is available at the end of the article
}

observed over the past several decades [1-3]. Subsequently, probiotics have been investigated in the prevention and treatment of allergy related diseases [3-8], with the strongest evidence emerging for the primary prevention of atopic dermatitis [3-5]. Throughout this paper we refer $\mathrm{AD}$, asthma and ARC as "allergy related diseases", recognising that not all presentations of these conditions are related to a classic IgE-mediated inflammatory process.

Randomised controlled trials (RCTs) testing probiotics in the prevention of childhood allergy related disease are heterogeneous and have used a variety of bacterial strains, administration regimes and varying ages of follow-up. 
Using information from the first published follow up for each trial, a recent meta-analysis concluded that probiotic administration is protective against the development of AD in infancy [3]. Among the studies with follow-up at or beyond 5 years of age, the greatest protective benefit of probiotics against $\mathrm{AD}$ appears to be in early childhood and it is less certain if this effect persists until school age [9-25]. Only one of these studies did not specify a maternal or family history of atopy as an inclusion criteria [9, $10]$, and there is therefore a particular need for further longer term follow-up studies to determine the ongoing effect of perinatal probiotics in general populations.

The Probiotics in the Prevention of Allergy among Children in Trondheim (ProPACT) study is a doubleblinded RCT investigating the effect of maternal probiotic supplementation on childhood allergy related diseases in a general population. The initial results of the ProPACT study demonstrated a clinically significant reduction in the cumulative incidence of $\mathrm{AD}$ at 2 years (OR $0.51,95 \%$ CI $0.30-0.87, p=0.013$ ), with the greatest reduction seen in children not considered at "high risk" for allergy related disease based on a negative family history [26]. Probiotic supplementation did not significantly affect the incidence of asthma, ARC or atopic sensitisation at 2 year of age, although the diagnosis of the former two diseases is uncommon and controversial at such a young age.

The participating children were re-contacted and reassessed at 6 years of age for the presence of allergy related diseases and allergic sensitisation. The aim of the current paper was to investigate the effect of maternal perinatal probiotic supplementation on the cumulative incidence of $\mathrm{AD}$ and $\mathrm{ARC}$ and prevalence of asthma and atopic sensitisation at 6 years of age.

\section{Methods}

\section{Participants and design}

The ProPACT study has been described in detail previously [26]. Briefly, 415 women living in Trondheim, Norway, were randomised to receive daily probiotic supplementation or placebo from 36 weeks gestation until 3 months postpartum. Probiotic supplementation consisted of $250 \mathrm{~mL}$ of low fat fermented milk containing $5 \times 10^{10}$ colony-forming units (CFUs) of Lactobacillus rhamnosus GG (LGG) and Bifidobacterium animalis subsp. lactis Bb-12 (Bb-12) and $5 \times 10^{9} \mathrm{CFU}$ of L. acidophilus La-5 (La-5). The equivalently tasting placebo milk was sterile and contained no probiotic bacteria. The study milk was consumed by the women both preand postnatally, and the children did not receive any probiotic supplementation as a part of this study.

Participants were requested to complete questionnaires regarding lifestyle factors during pregnancy and at 6 weeks, 1 year and 2 years postpartum. These questionnaires detailed family history of allergy related diseases, dietary and parental smoking habits, housing conditions, family structure and the general health of the children. A child health questionnaire focusing on the presence of allergic symptoms and antibiotic use was completed at 1,2 and 6 years. Information regarding mode of delivery was unavailable, although assumed to be unaffected by the intervention regime. Those who had not initially responded to the 6 year child health questionnaire were re-sent this questionnaire in October 2013, when the children were between 8 and 10 years of age and responders to this re-sent questionnaire were considered "late responders".

Families were encouraged to attend a clinical examination for $\mathrm{AD}$ prior to 1 year if the child developed an itchy rash which lasted for more than 4 weeks. At 2 and 6 years, all children were invited to attend a clinical examination, including a structured interview, and allergy testing consisting of skin-prick testing (SPT) and specific IgE (sIgE). This examination was conducted by specially trained nurses at the 6 year follow-up who were unaware of treatment allocation. Participants were unblinded after the publication of the 2 year follow-up results [26]. Prior to this, the participants and investigators were blinded to treatment allocation which was conducted by the Department of Applied Clinical Research at the Norwegian University of Science and Technology through a computer-generated randomisation list without restrictions.

The trial was approved by the Regional Committee for Medical Research Ethics for Central Norway (Ref. 09703) and the Norwegian Data Inspectorate (Ref. 2003/ 953-3 KBE) and the trial protocol is registered in ClinicalTrials.gov (identifier NCT00159523). Parents gave their written consent.

\section{Outcomes}

The primary outcomes of interest were: cumulative incidence of atopic dermatitis (AD) and allergic rhinoconjunctivitis (ARC), and the 12 month prevalence of asthma. Children who attended the clinical examination(s) were assessed for $\mathrm{AD}$ using the UK Working Party (UKWP) diagnostic criteria [27]. Children who were assessed under these criteria as having $\mathrm{AD}$ at any point up to 6 years were considered to ever have had $\mathrm{AD}$ in the cumulative incidence estimate.

The cumulative incidence of ARC was defined by a positive answer to the question "Has your child ever had hay fever or allergic rhinoconjunctivitis?" in the 1, 2 or 6 year questionnaire. Current asthma was defined as a positive answer to both questions "Has your child ever been diagnosed with asthma by a doctor?" and "In the past 12 months, has your child been treated with tablets, inhalers or other medications for wheezing, chest tightness or asthma?". These questionnaire based definitions 
were used in order to minimise the proportion of participants with missing data and vary from the clinical examination based definitions presented in the 2 year follow-up article (Additional file 1: Table S1). Prompted by the findings of other probiotic trials, we include here the cumulative incidence of wheeze defined by a positive answer to both questions "Has your child ever had whistling in the chest?" and "Has your child ever had episodes of wheezing or tightness in the chest?" and a history of a lower respiratory tract infection, subcategorised into bronchitis and pneumonia, in the 1, 2 or 6 year questionnaire.

Atopic sensitisation was assessed as a secondary endpoint and was defined as any SPT wheal $\geq 3 \mathrm{~mm}$ or any sIgE level $\geq 0.35 \mathrm{kUL}^{-1}$. Both SPT and sIgE testing was performed as described previously [26] according to the ISAAC II procedure [28] for the following allergens: mite, mould, cat and dog dander, birch, timothy (grass) and mugwort pollen, egg white, codfish, hazelnut, peanut and cow's milk.

\section{Statistical analysis}

All statistical analyses were conducted using Stata/IC 13.1. The sample size calculation and randomisation procedure has been previously reported [26]. Due to the presence of missing data, the intention to treat (ITT) analysis strategy [29] included a main analysis using multiple imputations by chained equations (MICE) under the assumption that the data is missing at random (MAR) and a pattern mixture model (PMM) analysis to assess the sensitivity of the conclusions to this assumption. One hundred $(m=100)$ imputed data sets were created for the MICE analysis using the following predictor variables: treatment allocation, family history of atopy, siblings, sex, paternal smoking, antibiotic use within the first year of life, parentally reported eczema, protocol compliance and disease outcomes at 2 and 6 years of age. Further details regarding the MI model are provided in Additional file 1. A complete case analysis is also presented which includes participants who submitted the 6 year health questionnaire and or attended the 6 year clinical interview.

Univariate logistic regression was used to assess the impact of maternal probiotic supplementation on each of the outcomes for both multiple imputed datasets and complete case analyses. Although potential confounders should be balanced in an RCT, an alternate logistic regression model including family history, sex and siblings was assessed because of their previously reported associations with allergic disease and slight imbalance in the latter two.

A missing not at random (MNAR) sensitivity analysis was conducted using the pattern-mixture model version of the user written Stata command rctmiss. A detailed explanation of this analysis is provided in the Additional file 1.

\section{Results}

\section{Participants}

Participating families were recruited between September 2003 and September 2005, and the initial 6 year follow up occurred from December 2009 to December 2011. The 6 year child health questionnaire was completed by 281 (67.7 \%) families and 163 (39.3\%) attended the clinical interview (Fig. 1), with no significant difference in attendance rates between the probiotic and placebo groups. Mean age of follow-up at the clinical examination was 6.3 years (SD 0.2 years) in both probiotic and placebo arms. The mean age of completion of the questionnaire was also comparable between treatment arms among both initial and late responders (data not shown).

The baseline data and characteristics of participants randomised to receive probiotic supplementation or placebo showed minimal differences between the treatment groups (Table 1). Differences considered to be of potential influence due to reported association with childhood allergic diseases included the higher proportion of males (49.7 vs $41.8 \%$ ) and children with older siblings (44.0 vs $39.0 \%$ in the probiotic group compared to the placebo group.

\section{Characteristics of participants followed-up at 6 years}

Compared to those lost to clinical follow up, the children who attended the 6 year clinical examination had older mothers, were less likely to have a father who smoked during their first year of life and to have received fish before 6 months of age, and were more likely to have a family history of atopy, an older sibling and study protocol compliance (Table 1). Additionally, the children sensitised and or diagnosed with $\mathrm{AD}$ at 2 years were more likely to have attended the 6 year examination (Table 1). Similar differences were observed between children with and without a completed 6 year questionnaire (details provided in Additional file 1: Table S2).

\section{Atopic dermatitis}

A trend towards a lower cumulative incidence of UKWP diagnosed $\mathrm{AD}$ in the probiotic group with an odds ratio (OR) of 0.64 (95 \% CI 0.39-1.07, $p=0.086$; NNT $=10$ ) was observed in the MICE analysis (Table 2). This finding was statistically significantly in the complete case analysis (OR 0.48, $95 \%$ CI 0.25-0.92, $p=0.027$; NNT = 6 ). The adjustment for the covariates family history, sex and presence of older siblings resulted in inconsequential changes in the calculated OR estimates and did not substantially improve the precision of the estimate (data not shown). 


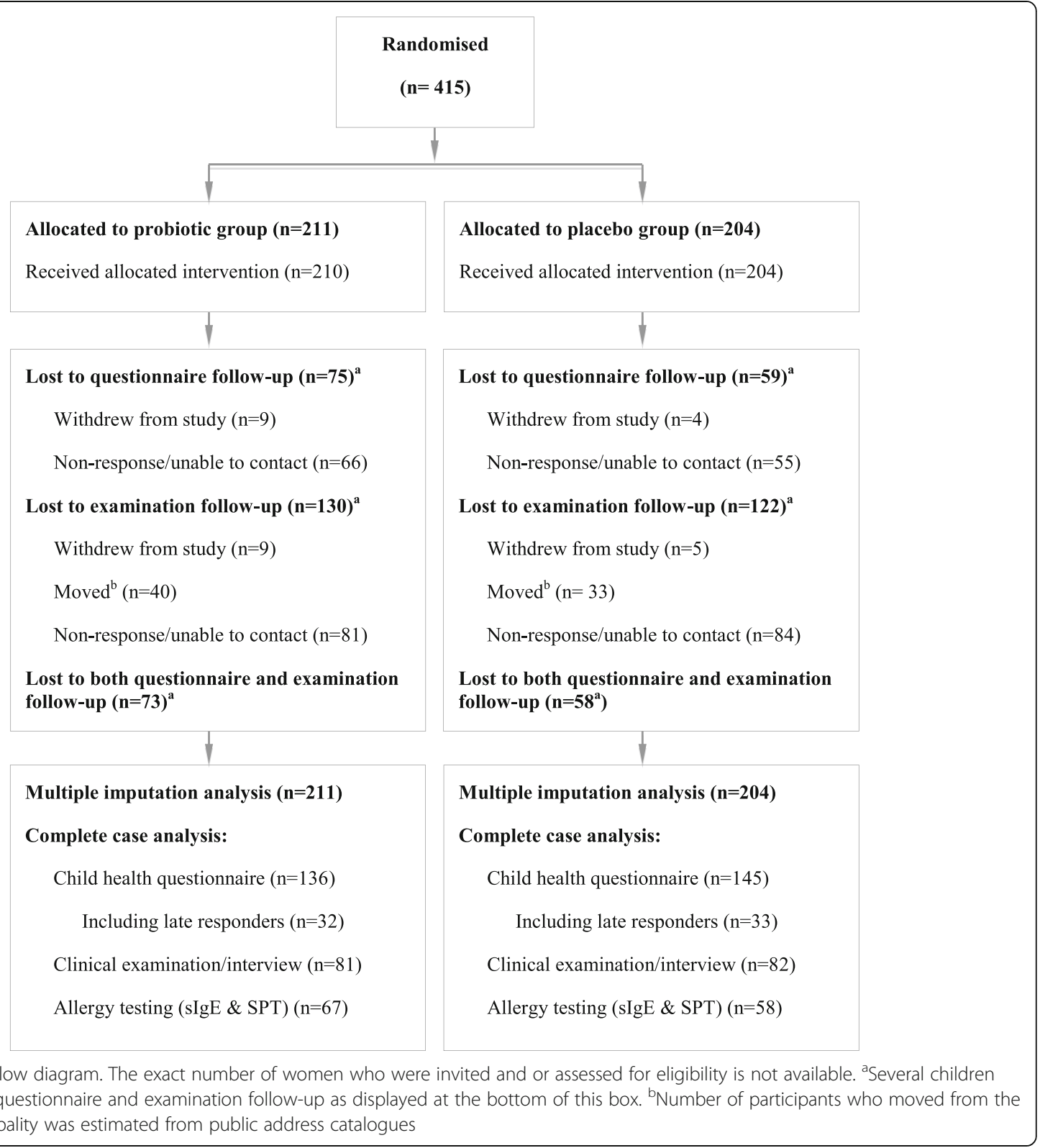

\section{Allergic rhinoconjunctivitis, asthma, sensitisation and lower respiratory tract infections}

There was no statistically significant difference observed between the cumulative incidence of ARC, 12 month prevalence of asthma or current atopic sensitisation in the MICE or complete case analyses (Table 2). Parental reported cumulative incidence of wheeze and lower respiratory tract infections were not influenced by the probiotic regime in observed cases or imputed estimates. There was a trend towards a lower cumulative incidence of pneumonia in the probiotic group (OR 0.41, $95 \% \mathrm{CI}$ $0.17-1.04, p=0.062$, Table 2 ) which was not statistically significant in the MICE analysis.

\section{Sensitivity analysis}

The results of the sensitivity analysis are provided in the Additional file 1. Briefly, if children with AD were more likely to be lost to follow-up in the probiotic group than the placebo group, then the preventative effect of probiotics would have been weakened.

\section{Discussion}

Maternal probiotic supplementation given to a general population of women appears to have an ongoing preventative effect on the cumulative incidence of $\mathrm{AD}$ until school age, however this did not reach statistical significance in the MICE analysis. There was no observed 
Table 1 Baseline data, characteristics and allergy related disease at 2 years

\begin{tabular}{|c|c|c|c|c|c|c|c|c|c|}
\hline & \multicolumn{4}{|c|}{ Comparison of treatment groups } & \multicolumn{4}{|c|}{ Comparison of drop out cases } & \multirow[b]{3}{*}{$p$-value ${ }^{t}$} \\
\hline & \multirow{2}{*}{\multicolumn{2}{|c|}{$\begin{array}{l}\text { Probiotic }(n=211) \\
n^{a}\end{array}$}} & \multirow{2}{*}{\multicolumn{2}{|c|}{$\frac{\text { Placebo }(n=204)}{n^{a}}$}} & \multirow{2}{*}{\multicolumn{2}{|c|}{$\begin{array}{l}\text { Attended } 6 \text { yr examination } \\
\mathrm{n}^{\mathrm{a}}\end{array}$}} & \multicolumn{2}{|c|}{ Drop-outs } & \\
\hline & & & & & & & $\mathrm{n}^{\mathrm{a}}$ & & \\
\hline \multicolumn{10}{|l|}{ Baseline data and characteristics } \\
\hline Age, mother (years), mean \pm SD & 191 & $30.1(3.9)$ & 189 & $30.3(4.4)$ & 162 & $30.7(3.9)$ & 218 & $29.8(4.2)$ & 0.024 \\
\hline Education, mother (yrs), mean \pm SD & 183 & $15.3(2.2)$ & 181 & $15.2(2.3)$ & 156 & $15.2(2.1)$ & 208 & $15.2(2.4)$ & 0.968 \\
\hline Education, father (yrs), mean \pm SD & 184 & $14.8(2.7)$ & 179 & $14.7(2.4)$ & 156 & $14.7(2.5)$ & 207 & $14.8(2.6)$ & 0.561 \\
\hline Birth weight $(\mathrm{g})$, mean $\pm \mathrm{SD}$ & 187 & $3662(478)$ & 176 & $3596(474)$ & 161 & $3626(466)$ & 202 & $3635(486)$ & 0.814 \\
\hline Sex (male), n (\%) & 193 & $96(49.7)$ & 191 & $80(41.8)$ & 163 & $76(46.6)$ & 221 & $100(45.3)$ & 0.151 \\
\hline Premature, n (\%) & 189 & $5(2.7)$ & 185 & $7(3.8)$ & 162 & $5(3.1)$ & 212 & $7(3.3)$ & $1.000^{c}$ \\
\hline Siblings, n (\%) & 207 & $91(44.0)$ & 200 & $78(39.0)$ & 163 & $82(50.3)$ & 244 & $87(35.7)$ & 0.003 \\
\hline Atopy in family, $\mathrm{n}(\%)$ & 207 & $152(73.4)$ & 200 & $148(74.0)$ & 163 & $127(77.9)$ & 244 & $173(70.9)$ & 0.115 \\
\hline Smoking mother ${ }^{\mathrm{d}}, \mathrm{n}(\%)$ & 204 & $16(7.8)$ & 200 & $19(9.5)$ & 163 & $13(8.0)$ & 241 & $12(9.1)$ & 0.686 \\
\hline Smoking father ${ }^{\mathrm{d}}, \mathrm{n}(\%)$ & 203 & $35(17.2)$ & 198 & $38(19.2)$ & 163 & $21(12.8)$ & 238 & $52(21.8)$ & 0.022 \\
\hline Breastfed $\geq 3$ months, $\mathrm{n}(\%)$ & 168 & $164(97.6)$ & 166 & $162(97.6)$ & 155 & $153(98.7)$ & 179 & $173(96.7)$ & $0.293^{c}$ \\
\hline At least one pet at home ${ }^{\mathrm{d}}, \mathrm{n}(\%)$ & 207 & $52(25.1)$ & 200 & $53(26.5)$ & 163 & $47(28.8)$ & 244 & $58(23.7)$ & 0.253 \\
\hline Used antibiotics ${ }^{\mathrm{d}}, \mathrm{n}(\%)$ & 161 & $35(21.7)$ & 159 & $34(21.4)$ & 152 & $34(22.4)$ & 168 & $35(20.8)$ & 0.739 \\
\hline Fish $\leq 6$ mo., $\mathrm{n}(\%)$ & 163 & $35(21.5)$ & 165 & $27(16.4)$ & 155 & $22(14.2)$ & 173 & $40(23.1)$ & 0.039 \\
\hline Vegetables $\leq 6$ mo., n (\%) & 166 & $84(50.6)$ & 166 & $105(63.3)$ & 156 & $90(57.7)$ & 176 & $99(56.3)$ & 0.791 \\
\hline Protocol compliance ${ }^{\mathrm{e}}, \mathrm{n}(\%)$ & 150 & $130(86.7)$ & 148 & $128(86.5)$ & 147 & $134(91.2)$ & 151 & $124(82.1)$ & 0.022 \\
\hline \multicolumn{10}{|l|}{ Allergy related disease at 2 years } \\
\hline Atopic dermatitis, $\mathrm{n}(\%)$ & 138 & $29(21.0)$ & 140 & $48(34.3)$ & 145 & $52(35.9)$ & 133 & $25(18.8)$ & 0.001 \\
\hline Allergic sensitisation ${ }^{f}, \mathrm{n}(\%)$ & 131 & $20(15.3)$ & 133 & $15(11.3)$ & 140 & $26(18.6)$ & 124 & $9(7.3)$ & 0.007 \\
\hline
\end{tabular}

Table 2 Prevalence and cumulative incidence at 6 years of allergy related diseases, wheeze and lower respiratory tract infections in the probiotic and placebo groups

\begin{tabular}{|c|c|c|c|c|c|c|c|c|}
\hline \multirow{3}{*}{ Allergy related disease } & \multicolumn{3}{|l|}{ Imputed estimates } & \multicolumn{5}{|c|}{ Observed cases } \\
\hline & \multirow{2}{*}{$\begin{array}{l}\text { Probiotic, } \mathrm{n}=211 \\
\%(95 \% \mathrm{Cl})\end{array}$} & \multirow{2}{*}{$\begin{array}{l}\text { Placebo, } n=204 \\
\%(95 \% \text { Cl) }\end{array}$} & \multirow[t]{2}{*}{ Odds ratio $(95 \% \mathrm{Cl})^{a}$} & \multicolumn{2}{|c|}{ Probiotic } & \multicolumn{2}{|l|}{ Placebo } & \multirow{2}{*}{$\begin{array}{l}\text { Odds ratio } \\
(95 \% \mathrm{Cl})^{\mathrm{a}}\end{array}$} \\
\hline & & & & $n / n$ & $\%(95 \% \mathrm{Cl})$ & $n / n$ & $\%(95 \% \mathrm{Cl})$ & \\
\hline \multicolumn{9}{|l|}{ Current disease } \\
\hline Asthma & $2.3(0.0-4.7)$ & $0.9(0.0-2.5)$ & $1.68(0.21-13.20)$ & $3 / 136$ & $2.2(0.7-6-7)$ & $1 / 145$ & $0.7(0.0-4.8)$ & $3.25(0.33-31.6)$ \\
\hline Allergic sensitisation & $30.0(21.2-38.8)$ & $28.0(18.8-37.1)$ & $1.11(0.62-1.96)$ & $23 / 80$ & $28.8(19.7-39.8)$ & 19/78 & $24.4(16.0-35.3)$ & $1.25(0.62-2.54)$ \\
\hline \multicolumn{9}{|l|}{ Cumulative incidence } \\
\hline Atopic dermatitis & $29.3(21.2-37.4)$ & $39.1(30.2-48.0)$ & $0.64(0.39-1.07)^{b}$ & $22 / 81$ & $27.2(17.3-37.1)$ & $36 / 82$ & $43.9(32.9-54.9)$ & $0.48(0.25-0.92)^{c}$ \\
\hline ARC & $21.6(14.6-28.6)$ & $18.8(12.0-25.7)$ & $1.19(0.66-2.16)$ & $22 / 134$ & $16.4(10.1-22.8)$ & $20 / 145$ & $13.8(8.1-19.5)$ & $1.22(0.64-2.37)$ \\
\hline Wheeze & $39.0(30.9-47.1)$ & $45.8(37.4-54.1)$ & $0.75(0.47-1.22)$ & $46 / 132$ & $34.9(26.7-43.0)$ & $55 / 142$ & 38.7 (30.7-46.8) & $0.85(0.52-1.38)$ \\
\hline LRTI (any) & $30.6(22.2-39.1)$ & $36.8(29.1-44.5)$ & $0.76(0.47-1.23)$ & $33 / 128$ & $25.8(18.1-33.4)$ & $40 / 138$ & $29.0(21.4-36.6)$ & $0.85(0.50-1.46)$ \\
\hline Bronchitis & $23.6(16.3-30.9)$ & $27.6(20.2-35.0)$ & $0.81(0.48-1.36)$ & 29/130 & $22.3(15.1-29.5)$ & $32 / 139$ & $23.0(16.0-30.1)$ & $0.96(0.54-1.70)$ \\
\hline Pneumonia & $10.2(4.5-15.9)$ & $15.4(9.4-21.4)$ & $0.61(0.29-1.32)$ & $7 / 129$ & $5.4(1.5-9.4)$ & $17 / 141$ & $12.1(6.6-17.5)$ & $0.42(0.17-1.04)^{d}$ \\
\hline
\end{tabular}


effect of probiotics on the cumulative incidence of ARC, the 12 month prevalence of asthma or current atopic sensitisation.

A significant proportion of cases of allergy related diseases occur in children who are otherwise considered not to be at "high risk" and therefore primary prevention strategies must also be assessed in general populations [30]. This long term follow-up of the ProPACT trial is an important addition to the literature concerning probiotics in the prevention of allergic disease as one of few studies to recruit participants from a general population $[7,8,29]$. The only other RCT to have reported long term follow-up in a general population observed no benefit of their probiotic regime on the prevalence of any allergic disease or the cumulative incidence of questionnaire defined $A D$ at $8-9$ years of age $[9,10]$. Their regime included Lactobacillus paracasei spp paracasei F19 supplementation given to children during weaning. In comparison, our study involved pre- and postnatal supplementation of a mixture of probiotics which included the L. rhamnosus GG (LGG) strain. Both LGG and pre- and postnatal regimes were found to be associated with reduced $\mathrm{RR}$ of $\mathrm{AD}$ on sub-group analysis in a meta-analysis [3]. Additionally, we report UK Working Party diagnostic criteria defined AD which is a more extensively validated method of diagnosis [31, 32].

Looking to other trials, five RCTs have assessed the cumulative incidence of AD at 5 years of age or beyond in "high risk" populations [11-23]. The trial presented by Kalliomaki et al. [11-13] and the Lactobacillus rhamnosus (HN001) arm of the study by Wickens et al. [14-16] report a significant reduction in the cumulative incidence of $\mathrm{AD}$, which is sustained, although reduced, at follow-up at 6 years. Together with the current study, these trials indicate that the beneficial effect of probiotics on AD is most pronounced in infancy and may continue into early childhood. Furthermore, they suggest that we are observing a true primary preventative effect, rather than an intervention which delays the onset of AD. Contrastingly, the preventative effect of probiotics seen at 2 years in the large RCT published by Kukkonen/ Kuitunen et al. $[17,18]$ showed no trend towards ongoing benefit on follow-up at 5 years. The Bifidobacterium animalis subsp. lactis (HN019) arm of Wickens et al. [14-16] and 2 other trials [19-23] demonstrated no significant effect of probiotics on the cumulative incidence of $\mathrm{AD}$ at any follow-up time point from 1 to 7 years of age. It is interesting to note that all of the studies with an observed ongoing effect administered a L. rhamnosus strain preand postnatally, and that if the child was breastfed, the postnatal supplementation was given solely to the mother during the first months with the exception of Kalliomaki et al. [11-13] where approximate $57 \%$ of participants opted to give the probiotic or placebo capsules directly to the newborn children. In contrast, studies without an ongoing effect have either administered probiotic species other than L. rhamnosus and or specified that the probiotic supplements were to be given directly to the children regardless of breastfeeding. Further research is required to investigate if these observations are coincidental or represent strain and or regime specific effects.

The lack of effect on asthma, ARC and atopic sensitisation may reflect a true lack of effect or that the current study is under-powered to observed smaller differences in less frequent diseases. This is a universal problem for probiotic trials reporting asthma as an outcome [8]. Two recent meta-analyses concluded that there is not enough evidence to support perinatal probiotic supplementation in the prevention of childhood asthma or wheeze $[7,8]$. Reassuringly, neither our study nor these meta-analyses found that probiotics increased the risk of asthma or wheeze, a concern which arose after long term follow-up by Kalliomaki et al. $[8,11]$ Whilst one of these meta-analyses suggested that probiotics may increase lower respiratory tract infections [8], our study does not support this conclusion. On the contrary, we observe a trend towards lower cumulative incidence of pneumonia in the probiotic group. Atopic sensitisation was found to be significantly reduced in a sub-group meta-analysis of regimes which combined pre- and postnatal administration [7]. Consistent with the ProPACT study, none of the individual longer term follow-up studies have observed a significant effect of probiotics on sensitisation at school age. Interestingly, Lactobacillus acidophilus was found to be associated with an increased rate of atopic sensitisation in a multivariate meta-regression analysis [7]. This observation requires further investigation and may, in part, explain the lack of effect of the probiotic regime on sensitisation in the ProPACT trial.

The major limiting factor of this RCT is the high proportion of missing data which naturally raises concerns regarding the generalisability of the results and introduction of bias. Following the four point ITT analysis strategy recommended by White et al. [29] we have attempted to follow-up all participants, performed a primary analysis using MICE and a sensitivity analysis using PMM. Both of the latter two models account for all randomised participants under a range of assumptions about the cause of missingness and in doing so attempt to minimise bias from covariate-related and outcome-related drop-out, respectively. The reasons for loss to follow-up are primarily unknown, however very few participants actively withdrew from the study. An estimated 73 participants had moved from the study region, which would have precluded their attendance at the clinical examination in a presumably random manner. A number of these participants were 
followed-up through the questionnaire. In terms of generalisability, the original ProPACT population was similar to the total PACT population, which in turn was representative of the general population in Trondheim, Norway [26]. At the 6 year follow-up, the remaining participants were more likely to have a family history of atopy, older siblings and a pet and less likely to have a father who smoked. As these differences were not large we believe that the results are still generalisable to westernised populations where there is a reasonably high rate of allergy related disease. The PMM sensitivity analysis is particularly pertinent in this case because atopic sensitisation and or a diagnosis of $\mathrm{AD}$ at 2 years are associated with both attendance at the 6 year clinical examination and a diagnosis of $\mathrm{AD}$ at 6 years. This raises suspicions that the data is partially MNAR which would lead to biased estimates under both the complete case and multiple imputations analysis models. The PMM analysis suggests that results of this study for ARC, asthma and atopic sensitisation would have only been affected if there was an unrealistically strong association between disease and missingness in a single treatment arm. On the other hand, the magnitude of the preventative effect attributed to probiotics for $\mathrm{AD}$ at 6 years must be considered with caution, as the observed benefit is sensitive to the assumption that the relationship between $\mathrm{AD}$ and loss to follow-up is essentially identical in both the probiotic and placebo groups. Regardless of whether the outcome variables are partially MNAR, the MICE estimates are expected to be less biased than the complete case analysis. Another limitation is that the participants were informed of their treatment allocation and the observed reduction in AD after publication of the results from the 2 year follow-up in 2010 [26], although we do not believe that this to have significantly affected the current results. Firstly, the knowledge of treatment allocation has not affected participant behaviour with equal numbers from the probiotic and placebo groups attending the clinical follow-up at 6 years. Secondly, the UKWP diagnosis was based on assessment by research nurses who were unaware of treatment allocation.

\section{Conclusions}

In conclusion, we have previously shown that perinatal maternal probiotic supplementation is effective in reducing the cumulative incidence of $\mathrm{AD}$ in children up to 2 years of age. The current study does not conclusively demonstrate an ongoing benefit, however there is a strong trend towards a reduced cumulative incidence at 6 years. This would suggest that perinatal probiotics prevent and do not mere delay the onset of $\mathrm{AD}$ in childhood. The cumulative incidence of ARC and prevalence of asthma and atopic sensitisation were unaffected by the probiotic regime at 6 years of age.

\section{Additional file}

Additional file 1: Includes (a) Table S1. Definition of asthma and allergic rhinoconjunctivitis used at 2 and 6 years; (b) Table S2: Baseline data, characteristics and allergy related diseases at 2 years for those who did and did not submit 6 year child health questionnaire; (c) Details of multiple imputation model and (d) Details of pattern mixture model sensitivity analysis. (PDF $629 \mathrm{~kb}$ )

\section{Abbreviations}

AD: Atopic dermatitis; ARC: Allergic rhinoconjunctivitis; ProPACT: Probiotics in the Prevention of Allergies among Children in Trondheim; slgE: Specific immunoglobulin E; SPT: Skin prick test; UKWP: UK Working Party diagnostic criteria for atopic dermatitis; ISAAC: International Study of Asthma and Allergies in Childhood; ITT: Intention to treat; MICE: Multiple imputation by chained equations; MAR: Missing at random; MNAR: Missing not at random; PMM: Pattern mixture model.

\section{Competing interests}

T.Ø., O.S., C.K.D and M.R.S. participated in seminars sponsored by Tine BA. All other authors declare that they have no conflict of interest.

\section{Authors' contributions}

OS, RJ and T $\varnothing$ designed the study and directed its implementation. MRS conducted the statistical analysis and drafted the manuscript. CKD contributed to the interpretation of results and writing of the manuscript. All authors were involved in the interpretation of the results, revision of draft manuscript and have approved the final manuscript.

\section{Acknowledgements}

We thank all the children and their parents for their participation in this study along with the project assistants, Guri Helmersen and Else Bartnes, Dr Anne $R ø$, and the midwives of the Trondheim region.

\section{Funding sources}

This study was funded by the Norwegian University of Science and Technology, the Norwegian Research Council, Nidarosfondet and Siemens Medical Solutions Diagnostics AS. Tine BA sponsored the study through supply of study milk and logistics of its distribution. Employees from funding sources played no role in the study design, data collection, data analysis, interpretation of the study results, or writing of the manuscript.

\section{Author details}

'Department of Public Health and General Practice, Faculty of Medicine, Norwegian University of Science and Technology (NTNU), Postboks 8905, MTFS, 7491, Trondheim, Norway. ${ }^{2}$ Department of Dermatology, St Olavs Hospital, Trondheim University Hospital, Trondheim, Norway.

Received: 27 March 2015 Accepted: 30 June 2015

Published online: 01 August 2015

\section{References}

1. Rautava S, Ruuskanen O, Ouwehand A, Salminen S, Isolauri E. The hygiene hypothesis of atopic disease-an extended version. J Pediatr Gastroenterol Nutr. 2004;38(4):378-88.

2. Wold AE. The hygiene hypothesis revised: is the rising frequency of allergy due to changes in the intestinal flora? Allergy. 1998;53(46 Suppl):20-5.

3. Pelucchi C, Chatenoud L, Turati F, Galeone C, Moja L, Bach JF, et al. Probiotics supplementation during pregnancy or infancy for the prevention of atopic dermatitis: a meta-analysis. Epidemiology. 2012;23(3):402-14.

4. Panduru M, Panduru NM, Salavastru CM, Tiplica GS. Probiotics and primary prevention of atopic dermatitis: a meta-analysis of randomized controlled studies. J Eur Acad Dermatol Venereol. 2015;29(2):232-42.

5. Fiocchi A, Pawankar R, Cuello-Garcia C, Ahn K, Al-Hammadi S, Agarwal A, et al. World allergy organization-McMaster university guidelines for allergic disease prevention (GLAD-P): probiotics. World Allergy Organ J. 2015;8(1):4.

6. Szajewska $\mathrm{H}$. Early nutritional strategies for preventing allergic disease. Isr Med Assoc J. 2012;14(1):58-62. 
7. Elazab N, Mendy A, Gasana J, Vieira ER, Quizon A, Forno E. Probiotic administration in early life, atopy, and asthma: a meta-analysis of clinical trials. Pediatrics. 2013;132(3):e666-676.

8. Azad MB, Coneys JG, Kozyrskyj AL, Field CJ, Ramsey CD, Becker AB, et al. Probiotic supplementation during pregnancy or infancy for the prevention of asthma and wheeze: systematic review and meta-analysis. BMJ. 2013;347:f6471.

9. West $C E$, Hammarstrom ML, Hernell O. Probiotics during weaning reduce the incidence of eczema. Pediatr Allergy Immunol. 2009;20(5):430-7.

10. West CE, Hammarstrom ML, Hernell O. Probiotics in primary prevention of allergic disease-follow-up at 8-9 years of age. Allergy. 2013;68(8):1015-20.

11. Kalliomaki M, Salminen S, Poussa T, Isolauri E. Probiotics during the first 7 years of life: a cumulative risk reduction of eczema in a randomized, placebo-controlled trial. J Allergy Clin Immunol. 2007;119(4):1019-21.

12. Kalliomaki M, Salminen S, Poussa T, Arvilommi H, Isolauri E. Probiotics and prevention of atopic disease: 4-year follow-up of a randomised placebocontrolled trial. Lancet. 2003;361(9372):1869-71.

13. Kalliomaki M, Salminen S, Arvilommi H, Kero P, Koskinen P, Isolauri E. Probiotics in primary prevention of atopic disease: a randomised placebocontrolled trial. Lancet. 2001;357(9262):1076-9.

14. Wickens K, Stanley TV, Mitchell EA, Barthow C, Fitzharris P, Purdie G, et al. Early supplementation with Lactobacillus rhamnosus HN001 reduces eczema prevalence to 6 years: does it also reduce atopic sensitization? Clin Exp Allergy. 2013;43(9):1048-57.

15. Wickens K, Black PN, Stanley TV, Mitchell E, Fitzharris P, Tannock GW, et al. A differential effect of 2 probiotics in the prevention of eczema and atopy: a double-blind, randomized, placebo-controlled trial. J Allergy Clin Immunol. 2008;122(4):788-94.

16. Wickens K, Black P, Stanley TV, Mitchell E, Barthow C, Fitzharris P, et al. A protective effect of Lactobacillus rhamnosus HN001 against eczema in the first 2 years of life persists to age 4 years. Clin Exp Allergy. 2012;42(7):1071-9.

17. Kukkonen K, Savilahti E, Haahtela T, Juntunen-Backman K, Korpela R, Poussa T, et al. Probiotics and prebiotic galacto-oligosaccharides in the prevention of allergic diseases: a randomized, double-blind, placebo-controlled trial. J Allergy Clin Immunol. 2007;119(1):192-8.

18. Kuitunen M, Kukkonen K, Juntunen-Backman K, Korpela R, Poussa T, Tuure T, et al. Probiotics prevent lgE-associated allergy until age 5 years in cesareandelivered children but not in the total cohort. J Allergy Clin Immunol. 2009;123(2):335-41.

19. Taylor AL, Dunstan JA, Prescott SL. Probiotic supplementation for the first 6 months of life fails to reduce the risk of atopic dermatitis and increases the risk of allergen sensitization in high-risk children: a randomized controlled trial. J Allergy Clin Immunol. 2007;119(1):184-91.

20. Prescott SL, Wiltschut J, Taylor A, Westcott L, Jung W, Currie H, et al. Early markers of allergic disease in a primary prevention study using probiotics: 2.5-year follow-up phase. Allergy. 2008;63(11):1481-90.

21. Jensen MP, Meldrum S, Taylor AL, Dunstan JA, Prescott SL. Early probiotic supplementation for allergy prevention: long-term outcomes. J Allergy Clin Immunol. 2012;130(5):1209-11. e1205.

22. Abrahamsson TR, Jakobsson T, Bottcher MF, Fredrikson M, Jenmalm MC, Bjorksten B, et al. Probiotics in prevention of lgE-associated eczema: a double-blind, randomized, placebo-controlled trial. J Allergy Clin Immunol. 2007;119(5):1174-80.

23. Abrahamsson TR, Jakobsson T, Bjorksten B, Oldaeus G, Jenmalm MC. No effect of probiotics on respiratory allergies: a seven-year follow-up of a randomized controlled trial in infancy. Pediatr Allergy Immunol. 2013;24(6):556-61.

24. Gorissen D, Rutten N, Oostermeijer C, Niers L, Hoekstra M, Rijkers G, et al. Preventative effects of selected probiotc strains on the development of asthma and allergic rhinitis in childhood. The Panda study. Clin Exp Allergy. 2014;44:1431-3.

25. Niers L, Martin R, Rijkers G, Sengers F, Timmerman H, van Uden N, et al. The effects of selected probiotic strains on the development of eczema (the PandA study). Allergy. 2009;64(9):1349-58.

26. Dotterud CK, Storro O, Johnsen R, Oien T. Probiotics in pregnant women to prevent allergic disease: a randomized, double-blind trial. Br J Dermatol. 2010;163(3):616-23.

27. Williams HC, Burney PG, Hay RJ, Archer CB, Shipley MJ, Hunter JJ, et al. The U.K. Working Party's diagnostic criteria for atopic dermatitis. I. Derivation of a minimum set of discriminators for atopic dermatitis. Br J Dermatol. 1994;131(3):383-96.
28. Weiland SK, Bjorksten B, Brunekreef B, Cookson W, Von Mutius E, Strachan D. Phase II of the international study of asthma and allergies in childhood (ISAAC II): rationale and methods. Eur Respir J. 2004;24(3):406-12.

29. White IR, Horton NJ, Carpenter J, Pocock SJ. Strategy for intention to treat analysis in randomised trials with missing outcome data. BMJ. 2011;342:d40.

30. Williams HC. Prevention of Atopic Eczema: a dream not so far away? Arch Dermatology. 2002;138:391-2.

31. Williams HC, Burney PG, Pembroke AC, Hay RJ. Validation of the U.K. diagnostic criteria for atopic dermatitis in a population setting. Brit $J$ Dermatol. 1996;135:12-7.

32. Brenninkmeijer EEA, Schram ME, Leeflang MM, Bos JD, Spuls P. Diagnostic criteria for atopic dermatitis: a systematic review. Epidemiology and Health Services Research. 2007;158:754-65.

\section{Submit your next manuscript to BioMed Central and take full advantage of:}

- Convenient online submission

- Thorough peer review

- No space constraints or color figure charges

- Immediate publication on acceptance

- Inclusion in PubMed, CAS, Scopus and Google Scholar

- Research which is freely available for redistribution 